\author{
Kazimierz S. MEREDYK, Professor \\ Faculty of Economics and Finance, University of Bialystok \\ e-mail: k.meredyk@uwb.edu.pl \\ ORCID: 0000-0002-8927-8978
}

DOI: $10.15290 /$ oes.2020.02.100.08

Motto:

The efficiency of economy is the function of universal knowledge and economic illumination.

\title{
THE FUNCTIONAL DIMENSION OF THE THEORIES OF ECONOMICS ${ }^{1}$
}

\begin{abstract}
Summary
Description of the research - The following paper analyses the methodology of economic sciences and hence has a meta scientific character. From the point of view of the general methodology of sciences, it is simultaneously descriptive and nomothetic and, in the light of the universal methods of inference, the deduction prevails in it.

The inspiration to undertake meta scientific analysis was the controversy over the efficiency of the modern economy, strategy and economic policy as well as methodological incoherence and insufficient implementation effectiveness of economic sciences. Professional analysis of the research method of a specific area (field) cannot be limited to the creative invention itself, omitting both the subject and functionality of the theories created. And this is the nature of the attempts to undermine the efficiency paradigm of economic sciences.

The problem is the methodological coherence (incoherence) of the economic sciences and, in a wider context, of the entire field of social sciences, consisting in the inability to conduct workshop research and leading to the multiplication of erroneous statements about the social process.

In order to make the analysis more in-depth, two specific problems were identified: 1) the problem of the subject of economic research; and 2) the problem of coherence of the workshop economy, which often comes down to the unconscious crossing of the limits of economics.
\end{abstract}

Keywords: the subject of economic research, the method of economic research, economic paradigm, the functionality of economics theories, the structure of economic function parameters

JEL classification: A11, B41

${ }_{1}^{1}$ Article received on 6 June 2019, accepted on 5 February 2020. 


\section{Introduction}

The subject of this analysis is the method of social sciences ${ }^{2}$, taking into consideration the methodology of economics. Thus, the elaboration is meta scientific in terms of character. From the point of view of the general methodology of sciences it is simultaneously descriptive and nomothetic, while among the universal interference types it possesses a mainly deductive character.

The inspiration of this study was the controversy over the efficiency of the modern economy, economic strategy and policy and the methodological incoherence and insufficient implementation efficiency of economic sciences. Their sources ought to be sought in the unprecedented dynamics of the modern society and the expansion of widely perceived social processes.

At the same time we notice the development of alternative, so-called heterodox economic theories such as behavioral economics or institutional economics [comp. Kiełczewski et al., 2017, pp. 36-50], which give the impression of creating economics without economics?! Therefore, it is necessary to hold methodological discussion and return to the roots. Thus, the constituent theorem of economics is the theory of management with its effectiveness paradigm.

As a result, there is discussion on the problem of methodological coherence (incoherence) of economic sciences, while in a wider context, also of the entire huge domain of social sciences - which relates to the workshop failure of the research and the proliferation of wrong conclusions.

For greater in-depth analysis two isolated specific problems were identified: 1) the problem of the subject of economic research (par. 2) and 2) the issue of workshop coherence of economics and, as it often happens, of the unconscious crossing of the limits of what is economic (par. 3 and 4). In fact, the methodological incoherence and workshop failure of economics frequently leads to design errors and faults in the structure of the created abstractions, i.e. the names, categories, rights, regularities, models and theories. ${ }^{3}$

For example, economists analyze economic processes in good faith and professionally, ${ }^{4}$ by creating application theories and models which are later used by politicians (the economic ones) and entrepreneurs. Simultaneously they dismiss the real (subject) and conventional borders between research areas. On the other hand, the representatives of other social sciences frequently analyze economic processes

\footnotetext{
2 It regards mainly economics, sociology, political science, psychology, pedagogy, history, and in a wider perspective it concerns also humanistic and artistic sciences.

3 Abstraction the essence of the activity of mind which lies in the isolation of common characteristics of various subjects, regardless of those aims that are important for the entity and in omitting those characteristics that are either different or irrelevant; the result is either creation or discovery (depending on the epistemological concept) of the concepts recognizing common features related to a certain type or genre [Stownik filozofii, 2004, p. 11]. Abstract science, abstractionism, the term specifying art that does not present the world of recognizable items separated from illustrating the reality; an abstract work is an autonomous, separate reality composed of the arrangement of lines, forms, colors or shapes [Wielke encyklopedia ..., 2002, p. 57].

${ }_{4}^{4}$ The aforementioned clause should be neutralized by using the clarification in principle.
} 
and at the same time attempt to question the proficiency limitations of the economic system. As Edwin M. Hartman from the New York University precisely described 'It is not calculation, but deliberation (reflection, caution) that ought to be the basis of the argumentation of not how to achieve what I want, but what to want (underlined by K.M.)" [Gasparski, 2017, p. 255].

Consequently, there is a multitude of inaccurate and controversial information concerning the social state of affairs in addition to imprecise forecasts and unfeasible economic projects. What is more, information failures of this type have cumulative character because it is regularly used in the process of individual and collective decision making. Therefore, one can assume that they also constitute the main reason of the cyclical economic and political catastrophes.

It is worthwhile emphasizing that scientific circles, including economists, rarely analyze methodological problems and reluctantly adopt critical attitudes towards their own achievements. The main reason is probably the considerable degree of abstraction and complexity of methodological analyses as well as the environmental domination of tolerant attitudes with reference to methodological rigors. After all, such meta science as the methodology of analyses/research, does not translate directly into implementation effects and at the same time increases the costs of the system functioning. Otherwise, it is easier to have positive convictions than be critical. ${ }^{5}$

Moreover, the R\&D sector in Poland presently is subject to the pressure of utilitarianism. Meanwhile, the utilitarian approach to the methodology and scientific research is a mere intellectual trap. The main function of science is the multiplication and systemic accumulation of knowledge, rather than its implementation and solution of real problems. Economics, as one of the oldest branches of the social sciences, is characterized by a relatively high level of system consistency supported by a clearly specified paradigm. It remains the theory rooted in the group of theories explaining social mechanisms. Contrary to common opinion, its main function is the creative invention, the creation of abstractions and the explanation of the reality, however it is not connected with the direct and immediate solution of all the economic problems.

Intense and rapid changes of present social structures are undoubtedly intriguing as they reveal new contradictions in the real sphere as well as previously unknown scientific dilemmas. For example, the dynamic growth of the global economy enforced the advancement of economic research, however over the last few decades they were the subject of criticism. Emphasis is laid upon the incompatibility of the

\footnotetext{
${ }^{5}$ The relation to methodology and methodologists is pointedly explained in the well-known statement of Roy F. Harrod: "I am afraid that while selecting this topic (subject and method of economics) I exposed myself to two serious charges/complaints: firstly, boredom and secondly pride. The speculations regarding the methodology are famous for being banal and wordy (...). Being called a bore, a methodologist may not sit behind the curtain of modesty. On the contrary, as a self-confident man, a methodologist remains faithful to own simplifications and is eager to consult everyone and criticize the achievements of others who (irrespective of the value of their works) will at least attempt to be creative; takes the position of the final interpreter of the past and decides upon the direction of the future results." [Blaug, 1995, p. 5].
} 
theoretical concepts to the reality. Meanwhile, the theory of economics (as each structured abstraction), is a new subject creation, i.e. a separate being in relation to the subject of the analysis. It is simply the derivative of the primary reality. Hence it may only extract the functionally most important elements and parameters of the primary real existence. However, it definitely does not concern all of them! Nevertheless, it is just a matter of choice and specification of the functionality, i.e. the methodological issue.

\section{Economy vs. economics}

The real world, which is composed of the natural process and human activity, is limitless! This means that it is impossible to both explore and steer it. The reality, by definition, remains an objective being that is independent from the explored subject.

Naturally, it is necessary to constantly undertake the studies concerning the real world, even realized in the stochastic convention, but the full recognition remains beyond the range of the analyzing entity. A man remains only with a thought and generalization. The empirical character of scientific research where it may be adopted (such as in natural, technical and economic sciences), is connected with the feedback between the generalization and the collection of actual information. An economist is, by necessity, moving towards the sphere of abstractions, theories and modeling, but at the same time is collecting and verifying economic information.

The similarity of the general subject of social research - the collectivity of people, may lead to the conclusion that the interdisciplinary differences have purely formal (organizational) character. On the one hand, the relevant differences between them are blurred. On the other hand, a society must be analyzed in various crosssections and aspects. Meanwhile, social sciences develop much faster than, for example, technical and natural sciences, and their subject of analysis has radically changed over the past few decades. The fact is that individual human activities are mainly purposeful. However, the collection of individual purposeful activities remains a non-homogenous collection, as the consequence of which the level of systemic purposefulness is decreased. Against this background methodological differences between particular areas and disciplines are formed.

The empirical character of certain sciences does not imply that experience is the only source of theoretical reflection. An alternative source that is used simultaneously in the research practice is deduction. Both conventions (based on induction and deduction) only indicate the possibility of selecting the primary source of information that enables the formation of the higher level of generalizations. These two conventions reveal only the local methodical preference of a scientist.

The organic, natural, social and economic chaos that coerces evolution and the adjustment of economic sciences to the expectations and postulates of the society members is something different than the theory of economics. Most formulated regularities, models and theories remain scientific ephemeris, but are neither applied nor become the subject of interest of the community. As the best example may 
invariably serve all the concepts in the sphere of economic policy ${ }^{6}$ which are formulated based on the current state of affairs, instead of the hypothetically adopted future state. Meanwhile, the presumption in statu nascendi may perform the function of the model assumption.

Evolution is considered by a natural scientist and process engineer as an irrelevant past state of the real state of affairs. In social sciences, the evolution of the subject of research (social processes and economy) is the presence. It means that the adequate (complete, full) description of the reality is impossible, owing to which there is constant search for new instruments and scientific trends and methods. Social sciences in the analytical perspective are more complex than technical and natural sciences. The quality of scientific research in the sphere of social sciences depends on the constantly imperfect methodological incapacity. Therefore, the implementation of knowledge from the domain of social sciences (economics, social and political sciences, social psychology, etc.) is a particularly complex process.

If we adopt the separation of the real existence (the reality and the universe), which is composed of items, thoughts and the society (the relations between people), it will be necessary to isolate three areas of scientific research: natural and technical sciences, social sciences and formal sciences (philosophy, mathematics, logic). ${ }^{7}$ Thus the subject of economic research are social processes, and in detail a certain cross-section of these processes known as economy and management.

Economic activity is the expression of limitless human activity and it adopts various forms, starting from the individual, necessary everyday activities that guarantee the existence up to complex technical and organizational forms. It can be connected to the cultivation of a garden near the house, small trade, contract work, company management as well as the storing and processing of trade information generated by the market.

Economy, which constitutes simultaneously a part of human activity and the subject of scientific research is subject to constant analysis, but it also needs to be controlled and have limited exuberance. After all, economic functions are not basic existential choices of a man, owing to which there may appear natural contradictions at the interface between them.

In the light of the above, economy is an institutionally limited and functionally ordered collection of repetitive human activities, as the result of which there are created such commercial values as direct services, intellectual services, artistic and literary works, entertainment spectacles and material goods.

Naturally, economy is not the only main and most important part of social activity, but a certain integral aspect of the activity of those people who undertake various activities for various reasons. In order to separate economic activities from

\footnotetext{
${ }^{6}$ The aforementioned comment regards probably all the concepts from the sphere of political activity.

7 The problem of all classifications lies in the adopted criteria of dividing the analyzed collections, i.e. the criteria regarding the isolation of their elements. These criteria do not guarantee the unambiguousness (logical purity) of the classification. For example, technical and economic sciences that make up the group of empirical sciences, are simultaneously the sciences that create their own formal level irrespective of the mega domain of formal sciences [Wielka encyklopedia..., 2003, pp. 572-574].
} 
the non-economic ones it is necessary to ascribe the so-called effectiveness functionality to a certain activity. However, it is obviously possible to ascribe to a certain activity in a process aspect a different functionality than that of the effectiveness type. It is always a local choice that means a formal determination of the specific type of an economic activity in the light of other types of human activity.

Therefore, economy remains one of numerous forms of human collective activity. It combines the individual efforts made by people in the process of creating commercial values including services and material goods that secure the existence. There should be added countable values. Through the study of economics sooner or later everyone will become mindful to the fact that the system of prices is the mechanism that compels economic units to adopt certain behavioural rules and compels them in an automatic way, without central management or a collective plan. This idea appears to each of us in due course with a complete sense of personal revelation. It is much later that we can discover the ancient truth. Perhaps it is not so ancient as this truth was initially discovered approximately 300 years ago. Adam Smith was one of the first people who understood it fully and is regarded as the first scientist who understood its dramatic consequences" [Blaug, 2000, p. 77].

It is worth emphasizing that among economic construction there is presently observed the domination of direct services and intellectual services which adopt the form of scientific, artistic and literary works, entertainment events as well as theories, models, projects and programs. However, primarily it is necessary to distinguish between an individual and collective economic activity. Thus, there remains only one step to generalization (the theoretical one).

In the collective scale, management adopts the form of a social element that is composed of the individual efforts of particular participants motivated by the constantly changing cultural surroundings. It means that the conscious shaping of economic activity is possible only to a limited degree. Hence the need for conscious and organized economic creation adopting the form of scientific creation.

The philosophical basis of the theory of economics has always been functionalism $^{8}$, in accordance with which all the abstractions created in empirical sciences are the generalizations of real dependencies between social phenomena. Therefore, it is necessary to accept the suggestion implying that economics in the empirical dimension is not only a certain type of intellectual creation, but simultaneously the creation that must adopt the form of a relatively specified formal system. Although

\footnotetext{
${ }^{8}$ Functionalism - in methodology, one of the views of 19th century positivists "according to whom in empirical sciences there is no place for seeking reasons and cause-and-effect relations of the analyzed phenomena, but it is only possible to confirm the functional relations between them; they believed that the concept of $<$ reasons $>$ is burdened by metaphysical (...) semantic tradition, while the explanation of the reasons is anthropomorphism, the essence of which is to transfer the human causation relation to the phenomena of nature and to perceive the reasons of phenomena in seeing the reasons of phenomena in the activity of certain forces; therefore, they believed that in science it is necessary to renounce the application of the concept of <reason> as scientifically useless and leading to metaphysical hypostasis and presented the argument implying that in empirical research one should not ask < why $>$ but $<$ how $>-$ and stop analyzing the functional relations between the analyzed phenomena" [Wielka Encyklopedia..., 2002, p. 445].
} 
the formation of new concepts of stable and constant progress and all types of prosperity are constantly observed, there is no social force and its theoretical manifestation that would guarantee sustainable and stable development, as the result of which the very concept of progress is changing.

The theory of economics does not describe or generalize all the essential economic regularities, nor does it create an adequate theory for the reality. After all, it is impossible to create such economic theory which (while having a proper level of knowledge and intellectual proficiency) would constitute the basis of efficient economic strategy and policy. The prediction of the events as well as the designing and programming of effective activities is particularly risky. Both formal and factual mistakes are evident.

They are most frequently corrected internally, in a natural way. Simultaneously there emerges the external criticism of economic theories that stems directly from the experiences of an economic policy. As one may assume its sources remain usually the natural inefficiencies of the real economic system that cause serious contradictions between the theory and practice and lead to the radicalization of social moods. These contradictions as well as the interrelated conflicts remain the inseparable element of social life. They do not depreciate the fundamental system of values and do not reduce the quality of the declared theories, but only draw one's attention to the necessity to improve them. Therefore, they absorb the social energy and require a reasonable political reaction.

Irrespective of the methodological issues, the implementation inefficiency of the theory is to a certain degree natural and is desired even in a workshop perspective. However, it may not cross the borders of particular research areas and individual knowledge and competences. Therefore, the alleged key mistake of economists the modelling of own abstractions simultaneously with the consistent usage of the paradigm of effectiveness.

Otherwise, economists themselves make symmetrical mistakes in relation to the representatives of other social spheres by starting non-economic research [Gołaszewska-Kaczan et al., 2017, pp. 164-174]. In such situations, the formal side of economic modelling is frequently undermined by not defining the problem and by not specifying the value of the suggested function as well as its variable and constant parameters. Thus, a free, unverifiable form of creative invention which is closer to humanistic and artistic sciences than to economic sciences is formed.

Firstly, in the formal perspective of economic research a frequently occurring problem is the imprecise formulation of the value of economic function which nevertheless comes from the paradigm of effectiveness.

Secondly, there is a problem related to the collection of direct independent variables created on the principles of creative invention or at the level of empirical research. In the subsequent stages of the research they are repeatedly verified and tested in a certain place and time.

Thirdly, formal weakness of the programming of economic research is the inadequate selection of constant function parameters. In this case the problem lies in the arbitrary subjective decision regarding the choice and the importance of 
particular parameters. The conscious activity (of a man or an institution) is certainly a part of the reality, but its causative force is governed by other rules than the regularities arising from the chaos.

\section{Economic function and its parameters}

Economic functionalism is a form of fictionalism" or "critical positivism", in compliance with the will of its main creator and thinker Hans Vaihinger (1852-1933) - Kant scholar and positivist who was underestimated by economists. The theory of economics in his nomenclature is considered as fiction or abstraction as it is presently named.

Economic theorem with its effectiveness paradigm creates a functional structure where the value of function is the commercial effect, outlay or the relation between them, which in the research practice means that these values may be used in a certain function also in the form of independent variables.

All of the economic concepts and relations at their source have stochastic character and are multi-layered. Therefore, for example, a collection of economic factors used in economic models and theories in the form of independent variables must be empirical, countable and have statistical relation with a certain, formulated function. Hence it is no coincidence that in a typical production function there are exploited also such variables as outlays and costs, whereas natural and political factors are recorded in the form of fixed parameters.

The undermining of scientific paradigm regards methodological issues and is most frequently connected with identifying abstractions and the reality (thought and action). Hence it frequently refers to the identification with two beings and a certain escape from being scientific (which invariably denotes the relation between abstraction and the reality, which in empirical sciences are clearly isolated. What is undermined is the basic assumption which constitutes the essence of what is economic instead of discussion on the evolution of economic sciences, their economic adequacy or formal consistency.

Other criteria are of secondary importance. They regard also economic criteria, rationality, effectiveness and efficiency. Therefore, the basic function of the theory of economics is formulated properly. It takes into consideration the values that are superior in relation to the criterion of effectiveness. Thus, economists may not be criticized for the lack of decency and moderation.

\footnotetext{
${ }^{9}$ For Vaihinger, fiction was connected with everything in mind which: 1) does not correspond to the reality but still 2) is necessary for living. There is constantly a multitude of fiction in science and philosophy: they include almost all the general concepts and theories, all the artificial classifications and definitions, all the schemes and models, all the concepts and abstractions, all the personifications and hypotheses (such as soul or force), the concepts of maths and mechanics (such as absolute space and time), various legal concepts (fictiones iuris), statistic (such as the concept of an average man), psychological concepts (the concept of mental powers), economic and ethical concept (such as the idea of freedom), natural (such as atom or ether), and particularly innumerable philosophical concepts and theories [Tatarkiewicz, 1970, pp. 104-105].
} 
Reasonable and moderate people, i.e. all the economists (hopefully) will ascertain with concern the increase of convictions over reason. After all, in the periods of ideological intensification the institutional system, including mainly spontaneous (informal) institutions have direct impact on the economy by causing irreversible damages and weakening development processes. A modern example is the cyclical recurrence of populism which appears to be one of the main sources of constant criticism of economic sciences.

In any case, the general form ${ }^{10}$ of the basic economic function adopts the form of effectiveness:

where:

$$
\mathrm{E}=f(\mathrm{Q}, \mathrm{N}, \mathrm{A}, \mathrm{S}, \mathrm{h}, \mathrm{a}, \mathrm{b} . .)
$$

$\mathrm{E}$ - effectiveness (FAG - the function of economic activity)

$\mathrm{Q}$ - economic effects

$\mathrm{N}$ - economic outlays

$\mathrm{A}, \mathrm{S}, \mathrm{h}$ - fixed parameters (A - axiological system, $\mathrm{S}$ - the system of motivation, $\mathrm{h}$ - the state of health).

The theory does not conform to the practice and does not fully reflect the reality. Thus, it is impossible to shape the reality solely based on $f$ the theory of management. After all, economy is the inseparable part of the entire social process which is composed of culture (convictions, norms and ideas) and policy. From the point of view of pragmatics and economic policy the problem regards the fact that the holistically considered social process has spontaneous character, i.e. functional and chaotic, and it is internally contradictory. Hence the typical economic problem remains system uncontrollability. In other words, the theory of management infected with the liveliness of the real world is incapable of formulating simplifications adequate for the reality and proper predictions.

The natural characteristic of any theory, including the theory of economics, is non-compliance with the realities. At any rate it regards all empirical sciences ${ }^{11}$ and is the source of constant and unauthorized criticism of economics and economists. Unjustified undermining of the paradigm of economic sciences develops in the best. ${ }^{12}$ Meanwhile, science understood as the way of understanding the reality is by its very nature entity that completely differs from the reality. Hence all the empirical (inductive) sciences isolated in accordance with the subject criterion of scientific

\footnotetext{
10 The general form of the function specifies the value of function, independent parameters (variables) and fixed parameters of function. However, it does not specify the character of the relation between the value of function and its arguments (comp. analytical and operational form of the function).

${ }^{11} \mathrm{It}$ is commonly assumed that economics, in accordance with the methodological criterion, is also an empirical (inductive) science although a considerable part of economic achievements, such as the theory of the functioning of the national economy and the theory of economic growth, have deductive character [Encyklopedia Powszechna, 1975, p. 235-236].

12 Otherwise, also economists take part in this activity! The reason of such state of affairs is the aforementioned autonomy arising from the definition of a method and methodology.
} 
research show only the preferences regarding the selection of the primary source of information.

A serious system hazard for economic research is the unceasing eagerness to initiate and formulate non-economic aims or/and purely formal ones that are distant from the issues closely related to the economy. Most frequently, the titles of projects and elaborations indicate the undertaking of such problems that are not directly connected with the economy. Such an approach signifies the ignorance of the basic assumption of economic function that is the paradigm of effectiveness.

The value of function itself may obviously regard a certain component of the effectiveness relation instead of the entire indicator. ${ }^{13}$ After all, regardless of the area of research and the efficiency of the local research and development system the basic law ought to be taken into consideration, i.e. it should be formulated and applied. ${ }^{14}$

The homo oeconomicus model in the professional (economic) perspective by its name is a methodological category, an abstraction "of a certain type of actions undertaken by people and referred to as management. At the level of the theory of economics, management is understood as a process, the starting point of which is the decision regarding the usage of available sources (resources) that an individual uses to realize the objectives adopted on their own. Therefore, the bomo oeconomicus model was defined by indicating the aim and manner in which this aim would be achieved." [Dzionek-Kozłowska, 2018, p. 8]. Therefore, the homo oeconomicus model is the basic right of economic sciences. It is not the case with economic practice which is not always and not necessarily rational, but it regards the theory of management!

In any case, the process efficiency of economic system requires clear definition and both conscious and professional usage of the effectiveness paradigm. Especially the state and dynamics of economic processes depends not only on the source of professional knowledge, but also (or even mostly) universal culture which is composed of the awareness of a statistic citizen and the interrelated attitudes. The universal understanding and wide practical acceptance of the economic paradigm reduces the temperature of social tensions and neutralizes economic contradictions.

It appears that the generalizing motion ought to be as follows: the source of economic and political argumentation to a greater extent ought to be axiology. Therein lies the eternal wisdom.

\footnotetext{
13 The general form of the function is specified by the function value, changeable parameters (independent) and fixed parameters of the function. However, it does not specify the character of the relation between the function value and its arguments (comp. analytical and operational form of the function). ${ }^{14}$ In western economics, since the second half of the 20th century, there has been observed very dynamic development of the theory and far-reaching segmentation and professionalization of this science. Both the processes were in an accelerated way assimilated by Polish academic economists. This process took place at the cost of weakening the interest in the theory of economics, the methodology of research and the history of economic thought. The research confirmed that this fact had negative consequences for the knowledge of economists and the internal consistency of their theoretical views and therefore for the position of Polish economics in the world [Karpińska-Mizielińska, Smuga, 2018, p. 131].
} 
Meanwhile, the functional form of economic regularities and statements decides both on the development of the theory of economics and on its implementation (operational) efficiency. ${ }^{15}$ Without it, an economic activity (regardless of the form, scale and type) would be solely restricted to intuition. Thus, it would adopt psychological character, organizational and irrational, and partly voluntary. Therefore, on the one hand the theory is the causative force of the real process, but on the other hand, it constitutes the generalization of information and an abstraction resulting from practice. ${ }^{16}$ In a purely epistemological perspective it promotes the consistency of the created theories, whereas in the implementation aspect, it reinforces general knowledge and the efficiency of the research itself.

The function of economic activity (FAG) obviously takes into consideration the factors emerging out of the economic surroundings such as the system of values, attitudes and behaviors, but solely in the form of fixed parameters instead of independent variables. In other words, the configuration of production factors (economic factors) by its very nature is a multi-level and chaotic system, which reflects the diversity of social forces. What makes a scientific process efficient is the hierarchy, a conscious choice of functions and priorities. The chief criterion of any conscious activities and choices are values, but not all of them may be considered at the same time. The efficiency of scientific research requires the organization of it.

Due to the fact that it is impossible to steer an economic process in an efficient way and the theory does not guarantee operational efficiency of the so-called decision-makers (causative entities), there remains only indirect influence by means of system axiological system and the development of culture.

Thus, the subject of the criticism of a theoretical system, irrespective of the type of a scientific domain, may be only the inconsistencies and indisputable formal mistakes, but not the chaos of the real world. The last among them has the character of the escaping horizon of the past events. Naturally, it is possible to construct models and theories on the basis of information stored a posteriori, but their usefulness is limited.

The methodological basis of the theory of economics has always been functionalism, in accordance with which all the abstractions created in empirical sciences are the generalizations of real relations between phenomena of both natural and social type. These relations constitute solely the hypothetical attempt to explain the real world, i.e. the world of beings and phenomena as such as well as the functional relations between them. As regards empirical sciences, the theory of cognition isolates the nominal and real world. The former, i.e. the world of thoughts, refle-

\footnotetext{
${ }^{15}$ Compare Paul Samuelson's concept of operationalism formulated in his doctoral thesis published in 1948 [Blaug, 1995, pp. 143-148].

${ }^{16}$ It is partly possible to agree with the opinion that "Broadly speaking, economics explains the motivations of people taking into consideration material living conditions and in what way these individual decisions translate into the behavior or markets and societies. By its nature, the theory relates to limiting the reality or creating a new <world> using assumptions of restrictive type [Zabkowicz, 2019, pp. 4-5]. Furthermore, economic research may obviously concern formal issues, the history of economic thought or economic history.
} 
ctions, language, abstractions, names, hypotheses, statements, rights, models and regularities, is the creation of homo sapiens. These dominate fluid feedback loops, but not one-sided cause and effect relationships.

As Paul Samuelson stated, there remains the issue of formulating "assumptions having operational meaning" [Blaug, 1995, pp. 145-146]. However, the problem is how to specify this operational meaning. However, operationalism and its instruments may not regard only one side of the functionality of the theory of economics, i.e. the procedure efficiency of testing the formulated assumptions. This efficiency results from the principle of unlimited, empirical testing of their accuracy, i.e. from the principle of falsifiability, as most $20^{\text {th }}$ century methodologists indicate. Meanwhile, it appears indispensable to increase the operational efficiency of the theory by ordering, improving and specifying the previously elaborated functions and models. After all, social chaos must be moderated to a certain degree, irrespective of the level of the awareness of its creators.

In the light of the above, the classification of economic research ought to be based on the criterion of functionality, but not causality. Therefore, it is crucial to isolate three types of these functionalities: abstraction, analysis and application. Thereby, it is necessary to isolate three types of formulated economic functions: the function per se, analytical functions and implementation functions. The former are chiefly the result of pure creative invention. The latter adopt the form of generalization of the results of inductive research and serve the recognition and explanation of the reality. Meanwhile, the implementation functions serve the solution of realistic problems, regardless of their scale and type.

The structure of causative forces of natural (experimental) systems, including social functions and economic expectations, is the arrangement that is changing in a chaotic way in time and space. After all, economy is a form of social activity and as such activity it has exuberant character. The tensions and conflicts are its fixed elements, whereas the process controllability remains clearly limited. What is more, ideological attitudes and the interrelated attempts to restrict the social element are unsuccessful. The point is that individual convictions themselves remain the creation of the natural institutional system.

Its essential part is obviously the axiological system which is as unstable and chaotic as direct economic variables. It may be used in many situations and it can explain with certain probability a certain state of affairs or/and certain economic tendency. However, it may not be used efficiently in the process of programming and planning activities. The programming and planning of activities constitute a form of prediction, which is uncertain because it serves predicting the statistic features of random phenomena.

Meanwhile, economists may not indiscriminately accept the restrictions concerning an economic process that arise from the sphere of attitudes, convictions and values that are not sanctioned in cultural or/and political terms. After all, the ethnology and economics create separate systems within the mega domain of social sciences, whereas the subject of their research is completely different. It means that 
their main functions are different and as the consequence there are different sets of their conventional analytical variables.

However, it a certain axiological system received such sanction, the restriction arising from it may be taken into consideration in an economic project in the form of fixed parameter of function.

\section{The function of common activity}

A typical case of careless going beyond the paradigm of effectiveness is the undertaking of axiological problems constituting other scientific disciplines in a widely considered area of social sciences [Richert-Kazimierska, 2018, pp. 16-32]. The model opposites of homo oeconomicus (a man who is national, efficient and effective) is homo eroticus (a man who is behavioral, neurotic and emotional).

Naturally, both abstracts have their individual, real references, regardless of the convictions, the represented system of values and the level of knowledge and the familiarity with the methodology of sciences. At the level of economic practice they remain inseparable, whereas in theory they create entirely different models. There is nothing to prevent the homo eroticus model to formalize and specify by giving it the form of function.

If there was decision to take the risk connected with the formation of a general form of such function, one would adopt as its value the universal activity regarding non-economic activities. After all, non-economic activity in practice is as precious as the activity serving effectiveness. It does not make sense to compare the importance of the former and the latter activity. Certain disciplines from the sphere of human and art sciences and particular scientific projects would have their own partial functions within the general Human Activity Function (FAP) if one assumed that social activity is an essential value and functionality.

Anyhow, among direct independent variables of social activity it is necessary to mention the locally dominating system of values, the motivational system and the state of social awareness. Meanwhile, as regards the second group of factors of social activity function that may play the role of its fixed parameters it is possible to isolate the health level, the state of the natural environment and the education level.

Therefore,

$$
\mathrm{HAF}=f(\mathrm{~W}, \mathrm{M}, \mathrm{S}, \mathrm{h}, \mathrm{a}, \mathrm{b} \ldots)
$$

where:

HAF - Individual Human Activity Function,

$\mathrm{W}$ - the system of values (axiological system),

$\mathrm{M}$ - motivational system,

$\mathrm{S}$ - the state of social awareness. 
Meanwhile, the examples of fixed parameters are:

$\mathrm{h}$ - the state of health,

a - the state of the natural environment,

$\mathrm{b}$ - the education level, etc.

Naturally, the structure of the parameters of function, changeable and fixed variables parameters within a certain research project remains the matter of local choice of the subject of the research. For example, if ecological hazards presently appear to be the most dangerous, it is necessary to take into consideration the protection of the natural environment among the fixed parameters of function. The commonly observed degradation of the natural environment is not only a global development hazard, but also an existential hazard.

The functioning of man on the Earth must take into consideration environmental changes, which was properly indicated in the concept of ecologism. ${ }^{17}$ Unfortunately, this structure is still not fully formalized and is composed of separate hypotheses, models and theories regarding, for example, the rate at which the earths climate is getting warmer, the dynamics of ice melting in Antarctica or Greenland or the degree of local degradation of the natural environment.

However, ecological hazards may undermine neither the economic paradigm nor any other paradigm consciously formulated within a certain discipline or/and scientific area. At any rate it may not take place earlier than before clear formulation of the paradigm of ecologism which would enable the creation of consistent and hopefully even partially verifiable theory indicating a hazard in a certain time interval for the existence of humankind. Such theory ought to indicate the instruments and ways of reducing the aforementioned danger, which would enable the introduction of proper fixed parameters of restriction type into economic theories and functions. After all, both concepts refer to entirely different research subjects.

The ethnological and axiological (or as its is commonly called) cultural surrounding of economy does not regard directly economics, but mostly other spheres of the mega sphere of social sciences such as political sciences, sociology, history, psychology, humanities and sciences related to art. In the subject cross-section of the research on social process these areas analyze and define the social relations and regularities forming at the edge of economy. Hence, they do not provide economists with direct independent variables of the formulated functions. However, they may be used (for example, as regards ecologism) in the form of fixed parameters.

Scientific activity, i.e. the creation of new theories, is connected with the interaction between the process of observing the reality and creating the so-called stylized facts and the previously stored knowledge (theory). In other words, the formation of new theories requires individual accumulation of the existing knowledge (studying)

\footnotetext{
${ }^{17}$ Ecologism renounces the domination of men in the natural world and exists in the opposition to political economic doctrines based on the idea of unlimited economic growth. The concept of man the maker (bomo faber) and economic man (bomo oeconomicus) is opposed to the concept of ecologism (bomo oecologicus) - an individual having new awareness and new ecological conscience [Baran, 2017, p. 7].
} 
which means getting to know in-depth the specialist language and its creation determining the formulation of original reflections in the form of names, abstractions and hypotheses as well as statements, rights and models. Thus, the creation of the system of scientific research and their implementation starts at the level of a language.

Naturally, the system of scientific research is not a system based on effectiveness, but by its very nature it has functional dimension, similarly to any real social activity. Eo ipso a functional system includes also the methodology of scientific research!!!, regardless of the subject of the research.

\section{Conclusions}

1. The project and the research in the domain of economic sciences is invariably a partial function of the general function of effectiveness. Except for meta science (the methodology of economics, the history of economic thought) and the disciplines combined in organizational terms such as economic history. Otherwise, such project regards other social sciences formulating different functions.

2. The collection of independent variables used in a certain economic project is, by nature, composed of the variables that directly specify the dynamics of effectiveness, i.e. the effects and outlays.

3. The institutional limitations of the economic process arising from the adopted system of values and legislative norm at the level of an economic project adopt the form of fixed parameters of function.

4. The process of creating and accumulating intellectual capital has cooperative character (instead of competitive), which means that those competition mechanisms that are well-known and commonly used in the sphere of art and scientific research have limited use.

\section{References}

Baran B., 2017, Wspótczesne wyzpwania ekologiczne - w kierunku bomo oecologicus, „Optimum. Studia ekonomiczne”, nr 6(90), s. 3-11, DOI: 10.15290/ose.2017.06.90.01.

Blaug M., 1995, Metodologia Ekonomii, Wydawnictwo Naukowe PWN, Warszawa.

Blaug M., 2000, Teoria ekonomii. Ujecie retrospektymne, Wydawnictwo Naukowe PWN, Warszawa.

Dzionek-Kozłowska J., 2018, Model homo oeconomicus, Wydawnictwo Uniwersytetu Łódzkiego, Łódź.

Encyklopedia Powszechna PWN, 1975, Państwowe Wydawnictwo Naukowe, Warszawa. Gasparski W.W., 2017, Ekonomia $i$ zarzadzanie z filozoficznej perspektyny - przeglad zagadnień..., [w:] Etyka i ekonomia. W strone nowego paradygmatu, Mączyńska E., Sójka J. (red.), PTE, Warszawa. 
Gołaszewska-Kaczan U., Grześ A., Kruk M., 2017, Social Responsibility of Universities: The Case of the Faculty of Economics and Management University of Bialystok, „Optimum. Studia Ekonomiczne”, nr 5(89), s. 164-174, DOI: 10.15290/ose.2017.05.89.11.

Karpińska-Mizielińska W., Smuga T., 2018, Polscy ekonomiści akademiccy okresu transformacji. Kilka reflekesji na tle wynikón badań, „Optimum. Economic Studies”, nr 4(94), s. 115-132, DOI: 10.15290/oes.2018.04.94.10.

Kiełczewski D., Poskrobko T., Matel A., 2017, Choice Architecture in Sustainable Consumption Policy, „Optimum. Studia Ekonomiczne”, nr 5(89), s. 36-50, DOI: 10.15290/ose.2017.05.89.03.

Richert-Kazimierska A., 2018, Dyskryminacja versus admiracja. Pracownicy w starsyym wieku w nybranych teoriach $i$ koncepijach ekonomicznych, "Optimum. Economic Studies”, nr 1(91), s. 16-32, DOI: 10.15290/oes.2018.01.91.02.

Stownik filozofii, 2004, Aduszkiewicz A. (red.), Świat Książki, Warszawa.

Tatarkiewicz W., 1970, Historia Filozofii, PWN, Warszawa.

Wielka Encyklopedia PWN, 2002, Wydawnictwo Naukowe PWN S.A., Warszawa, tom 9 .

Wielka encyklopedia PWN, 2003, Wydawnictwo Naukowe PWN, Warszawa, tom 13.

Ząbkowicz A., 2019, Cyy istnieje ekonomia kapitalizmu? „Optimum. Economic Studies”, nr 1(95), s. 3-18, DOI: 10.15290/oes.2019.01.95.01. 